\title{
The effect of L-Carnitine on Sodium Valproate-Induced Physiological Disturbances in Rats
}

\author{
Fahmy G. Elsaid ${ }^{1,2}$ and Fawzya E. Zeghiebr ${ }^{1}$ \\ ${ }^{1}$ Zoology Department, Faculty of Science, Mansoura University, Egypt. \\ ${ }^{2}$ Life Science Department, Faculty of Science, King Khalid University, KSA
}

\begin{abstract}
:
Background: Chronic treatment with sodium valproate (VPA) can lead to elevation of specific oxidative metabolites that associated with the drug's toxicity.

Results: Valproate exposure leads to an increase in reactive oxygen species (ROS). The levels of lipid peroxidation (malondialdehyde), and lipid profile variables (cholesterol, phospholipids, triglycerides and free fatty acids) were significantly increased ( $<<0.001)$ in orally administrated rats with sodium valproate at $400 \mathrm{mg} / \mathrm{kg}$ body weight/day. Also the deflection in the activities of catalase (CAT), lactate dehydrogenase (LDH) and $\mathrm{Na}, \mathrm{K}$-ATPase was registered where CAT, LDH and Na-K, ATPase activities were decreased $(\mathrm{p}<0.001)$ in rats under VPA treatment compared to the controls. These changes were more pronounced in valproate 60 days treated group than in valproate 30 days treated group. Oral administration of l-carnitine (L-CAR) at $300 \mathrm{mg} / \mathrm{kg} \mathrm{b}$. w. /day showed alleviation in all metabolic and physiologic changes in rats treated with sodium valproate. L-CAR supplementation might be recommended for human especially for epileptic persons subjected for long term to sodium valproate treatment.

Key words: Sodium valproate, L-carnitine, epilepsy, lipid profile, Malondialdehyde, catalase, Lactate dehydrogenase and $\mathrm{Na}, \mathrm{K}$ - ATPase activities, muscle, brain, bone and liver.
\end{abstract}

\section{Introduction}

Sodium valproate (VPA) is a major anti-epileptic drug with a broad spectrum of anti-epileptic activity. It has been the drug of choice in the treatment of most forms of primary generalized epilepsies and is also efficient against partial seizures (Rowan, 1997). The mechanism of action of valproate has yet to be fully elucidated. Much attention has been focused on the inhibitory central nervous system neurotransmitter $\gamma$-aminobutyric acid (GABA).VPA pharmacological action includes increase of $\beta$ - aminobutyric acids levels (Loscher and Vetter, 1985) and decrease of repetitive firing of action potentials (MacLean and Macdonald, 1986). Moreover, antiepileptic drugs may cause the changes in the oxidant/antioxidant system of the body. Valproic acid exposure leads to an increase in reactive oxygen species (ROS) (Defoort et al., 2006).

The main issues of concern with VPA have been hematological toxicity, teratoge- nicity and idiosyncratic hepatotoxicity (DeVane, 2003). Several findings and investigations are in favor of oxidative stress mechanism playing a role as a result of reactive oxygen species (ROS) over production and/or compromised antioxidant capacity (Sabayan et al., 2007). A study demonstrated that a single dose of VPA in rats led to a dose-dependent elevation in plasma and liver levels of the endogenous lipid peroxidation marker (Tong et al,. 2003). Oxidative stress is the cytotoxic consequences of ROS which are generated as by prevented by simultaneous administration of free-radical scavengers and support the concept that VPA hepatotoxicity is due to lipid peroxidation (Buchi et al., 1984). Also increased oxidative stress is associated with hypercholesterolemia (Dhalla et al., 2000). Oxidative damage to lipid, protein and DNA in the neuronal system may cause dysregulation of membrane transport mitochondrial 


\section{The effect of L-Carnitine on Sodium Valproate-Induced........}

energy production and gene expression among others (Fernandez-Checa et al. 1998; Cadenas and Davies, 2000; Marnett, 2000). On the other hand, new findings revealed that acute VPA-hepatotoxicity involves oxidative stress through the combination of ROS production and GSH depletion; however, VPA associated oxidative stress proceeds hepatotoxicity (Tong et al., 2005).

\section{Protective Effect of L- carnitine (CARN):}

Carnitine is evident in highest concentration in products derived from red meat and milk. L-CAR deficiency has been observed in metabolic diseases such as fatty acid oxidation disorders, and mitochondrial disorders (Coulter, 1995). L-CAR supplementation is potentially beneficial to patients with valproate-induced hepatotoxicity (Bohan et al., 2001). L-carnitine is an antioxidant and prevents the accumulation of end products of lipid oxidation (Fabriello and Calabrese, 1988; Lowitt et al., 1995). In addition, LCAR is transported to skeletal and cardiac muscles after its major production in liver and kidney (Brevetti and Perna, 1992; Visioli et al., 1992). It plays important physiological roles, shuttling the long-chain fatty acids across the inner mitochondrial membrane for $\beta$-oxidation and ATP production in peripheral tissues. Also, it translocates acetyl-CoA into cytoplasm during acetyl-l-carnitine transport out of mitochondria. In addition, it is a cofactor of several enzymes necessary for the transformation of free long fatty acids (FFA) to acylcarnitine and their transport across the inner mitochondrial membrane into the mitochondrial matrix (Kobayashi and Fujisawa, 1994; Uzeil et al., 1988 and Ramsay, 1999). A large amount of oxygen is consumed in this reaction and ATP is synthesized in the steps of electron transport chain and oxidative phosphorylation. Oxygen is reduced to $\mathrm{H}_{2} \mathrm{O}$ at the end of TCA cycle and, then, oxygen concentration decreases, thus ROS formation is reduced (Mayes, 2000). L-carnitine prevents oxidative stress and regulates nitric oxide, the cellular respiration (Brown, 1999) and the activity of enzymes involved in defense against oxidative damage (Kremser et al., 1995).
Also, 1-carnitine has a protective effect on the activity of mitochondrial enzyme succinate dehydrogenase as well as the activity of the antioxidant enzymes, catalase and superoxide dismutase against 3-NPA-induced neurotoxicity (Binienda and Ali, 2001). L-CAR, an antioxidant, can protect these CAT from further peroxidative damage and is very effective in normalizing age-associated alterations (Kalaiselvi and Panneerselvam, 1998).

L-CAR administration has been shown earlier to have a positive influence on skeletal muscle function (Brevetti et al., 1989). This effect has led to the use of carnitine in various muscle diseases as well as heart deficiency. So it may be of importance to overcome the problem of muscle fatigue (Acker et al., 1986). Continuous stimulation of untrained muscle may be expected to induce fatigue, which is partly due to accumulation of lactic acid. Now carnitine is being used as a therapeutic agent to improve exercise (Brevetti et al., 1989). There was also a recent report of improved survival associated with intravenous supplementation of carnitine in patients with severe and symptomatic valproate-induced hepatotoxicity (Bohan et al., 2001). So, the alterations of lipid peroxidation, lipid profiles and enzymatic activities were studied in different rat's organs in relation to the detoxifying effects of l-carnitine on sodium valproate administered rats.

\section{Material and Methods}

\section{Experimental protocol}

Twenty five male albino rats weighing between 150-160g were used in this study. The animals were randomized and divided into five groups ( $\mathrm{n}=5$ in each group). Group I (Control) animals served as control. Groups II (VPA 30d) and III (VPA 60d) animals were treated with sodium valproate (VPA) (400 mg/kg body weight) every day orally by a stomach tube (Ishikura et al. 1996) for 30 and 60 days, respectively. Groups IV (VPA 30d \& L-CAR) and V(VPA 60d \& L-CAR) animals treated with sodium valproate at the same dose at groups II and III but also received L-CAR at $300 \mathrm{mg} / \mathrm{kg}$ body weight 
(Dayanandan et al. 2001) orally administered by stomach tube for 30 and 60 days, respectively. At the end of the experimental periods, animals were sacrificed by decapitation. Muscle (right gastrocnemius muscle), brain, bone (right femoral bone) and liver tissues were excised and homogenized in distilled water for the determinations of biochemical parameters.

Methodology:

The levels of malondialdehyde (MDA) (Ohkawa et al., 1979), total lipids (Frings et al., 1972) cholesterol (Zlatkis et al., 1953), phospholipids (Baginiski et al., 1972), triglycerides (Foster and Dunn 1973), free fatty acids (Falholt et al., 1973) catalase (Sinha, 1972), Na,K- ATPase (Bonting, 1970) and Lactate dehydrogenase (LDH) activity was determined according to Raabo (1963) were analyzed in the investigated organs.

\section{Statistical Analysis}

The findings were expressed as the mean \pm SD. Statistical and correlation analyses were undertaken using the One-way ANOVA followed by post-hoc LSD (Least Significant Difference) test. A $\mathrm{P}$ value $<0.05$ was accepted statistically significant. Statistical analysis was performed with Statistical Package for the Social Sciences for Windows (SPSS, version 11.0, Chicago, IL, USA).

\section{Results}

The levels of lipid profiles such as total free fatty acids, total lipids, triglycerides, cholesterol and phospholipids in the sera are shown in table 1 . The levels of malondialdehyde (MDA), triglycerides and phospholipids in muscle, brain and liver are shown in table 2, and bone MDA are also shown in table 2. In addition, table 3 illustrates the enzymatic activities of CAT, Na-K ATPase and $\mathrm{LDH}$ in muscle, brain, liver and bone tissues in different groups.

In the status of antioxidants, a decrease of catalase with a concomitant increase in the rate of MDA was observed in the sodium valproate (Groups II and III) treated rats when compared with the control (Group I). The alleviation of LDH and Na,K-ATPase activities were observed in group IV (VPA 30d \& L-CAR) and group V (VPA 60d \& LCAR) as compared to their matched rats (Groups II and III) respectively. The levels of total free fatty acids, cholesterol, phospholipids and triglycerides were increased significantly in the sodium valproate treated rats (Groups II and III) compared to the group I. The group IV (VPA 30d \& L-CAR) and group V (VPA 60d \& L-CAR) showed significantly lower levels of total free fatty acids, cholesterol, phospholipids and triglycerides when compared with the sodium valproate treated rats (Groups II and III).

Table (1): Serum total free fatty acids (mmol/l), total lipids, triglycerides, cholesterol and phospholipids (mg/dl) in different groups:

\begin{tabular}{|l|l|l|l|l|l|}
\hline Parameters & $\begin{array}{l}\text { (group I) } \\
\text { Control }\end{array}$ & $\begin{array}{l}\text { (group II) } \\
\text { VPA 30d }\end{array}$ & $\begin{array}{l}\text { (group III) } \\
\text { VPA 60d }\end{array}$ & $\begin{array}{l}\text { (group IV) } \\
\text { VPA 30d } \\
\text { \& L-CAR }\end{array}$ & $\begin{array}{l}\text { (group V) } \\
\text { VPA 60d } \\
\text { \& L-CAR }\end{array}$ \\
\hline Total free fatty acids & $0.05 \pm 0.09$ & $0.69 \pm 0.01^{\mathrm{c}}$ & $1.04 \pm 0.01^{\mathrm{c}}$ & $0.37 \pm 0.04^{\mathrm{c}}$ & $0.45 \pm .02^{\mathrm{c}}$ \\
\hline Total lipids & $483.0 \pm 19.9$ & $738.8 \pm 23.4^{\mathrm{c}}$ & $1206 \pm 12.1^{\mathrm{c}}$ & $587 \pm 5.3^{\mathrm{c}}$ & $703.2 \pm 19.1^{\mathrm{c}}$ \\
\hline Triglycerides & $233.8 \pm 14.4$ & $528.3 \pm 54.9^{\mathrm{c}}$ & $696.9 \pm 25.3^{\mathrm{c}}$ & $397.9 \pm 22.1^{\mathrm{c}}$ & $516.1 \pm 17.9^{\mathrm{c}}$ \\
\hline Cholesterol & $82.5 \pm 4.6$ & $125.3 \pm 3.1^{\mathrm{c}}$ & $164.1 \pm 5.8^{\mathrm{c}}$ & $104.9 \pm 2.2^{\mathrm{c}}$ & $109.8 \pm 5.4^{\mathrm{c}}$ \\
\hline Phospholipids & $35.4 \pm 3.1$ & $74.4 \pm 39^{\mathrm{c}}$ & $87.9 \pm 4.6^{\mathrm{c}}$ & $42.6 \pm 1.5^{\mathrm{c}}$ & $56.1 \pm 6.6^{\mathrm{c}}$ \\
\hline
\end{tabular}

Data expressed mean $\pm \mathrm{SD},{ }^{\mathrm{a}} \mathrm{P}<0.05,{ }^{\mathrm{b}} \mathrm{P}<0.01$ and ${ }^{\mathrm{c}} \mathrm{P}<0.001$ 
Table (2): Malondialdehyde (MDA) (nmole/g tissue) level, triglycerides, cholesterol and phospholipids (mg/100g tissue) levels in liver tissues:

\begin{tabular}{|c|c|c|c|c|c|c|}
\hline 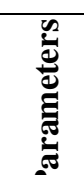 & Parameters & $\begin{array}{l}\text { (group I) } \\
\text { Control }\end{array}$ & $\begin{array}{l}\text { (group II) } \\
\text { VPA 30d }\end{array}$ & $\begin{array}{l}\text { (group III) } \\
\text { VPA 60d }\end{array}$ & $\begin{array}{l}\text { (group IV) } \\
\text { VPA 30d } \\
\text { \& L-CAR }\end{array}$ & $\begin{array}{l}\text { (group V) } \\
\text { VPA 60d } \\
\text { \& L-CAR }\end{array}$ \\
\hline \multirow{3}{*}{ 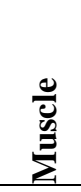 } & MDA & $6.2 \pm 0.9$ & $17.9 \pm 1.0^{\mathrm{b}}$ & $43.1 \pm 11.4^{\mathrm{c}}$ & $12.9 \pm 2.1$ & $14.3 \pm 1.7^{\mathrm{c}}$ \\
\hline & Phospholipids & $305.9 \pm 9.3$ & $760.2 \pm 43.4^{\mathrm{c}}$ & $1064.8 \pm 95.8^{\mathrm{c}}$ & $443.0 \pm 33.9^{c}$ & $608.6 \pm 13.6^{c}$ \\
\hline & Triglycerides & $341.9 \pm 10$ & $608.1 \pm 6.7^{\mathrm{c}}$ & $725.1 \pm 43.0^{\mathrm{c}}$ & $445.2 \pm 22.4^{\mathrm{c}}$ & $593.1 \pm 48.3^{\mathrm{c}}$ \\
\hline \multirow{3}{*}{ 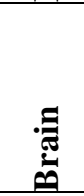 } & MDA & $31.0 \pm 0.8$ & $42.8 \pm 2.9^{\mathrm{b}}$ & $84.4 \pm 7.7^{\mathrm{c}}$ & $43.6 \pm 2.5$ & $54.5 \pm 8.3^{c}$ \\
\hline & Phospholipids & $559.3 \pm 37.3$ & $1249.9 \pm 135.3^{c}$ & $1603.9 \pm 181.9^{c}$ & $778.8 \pm 102.9^{c}$ & $1020.6 \pm 109.9^{c}$ \\
\hline & Triglycerides & $273.2 \pm 12.4$ & $555 \pm 31.3^{\mathrm{c}}$ & $728.1 \pm 22.6^{c}$ & $472.1 \pm 17.9^{c}$ & $595.1 \pm 21.6^{c}$ \\
\hline \multirow{3}{*}{$\stackrel{\grave{J}}{د}$} & MDA & $15.4 \pm 2.5$ & $67.2 \pm 19.1^{\mathrm{b}}$ & $85.6 \pm 6.1^{c}$ & $27.31 \pm 1.0^{\mathrm{c}}$ & $42.4 \pm 4.1^{\mathrm{c}}$ \\
\hline & Phospholipids & $191.5 \pm 5.1$ & $433.4 \pm 15.9^{c}$ & $670.3 \pm 16.8^{c}$ & $197.4 \pm 5.9^{c}$ & $378.2 \pm 18.3^{\mathrm{c}}$ \\
\hline & Triglycerides & $211.4 \pm 11.3$ & $609.9 \pm 29.1^{c}$ & $793.4 \pm 52.3^{\mathrm{c}}$ & $316.1 \pm 19.1^{\mathrm{c}}$ & $414.4 \pm 30.2^{c}$ \\
\hline bone & MDA & $5.2 \pm 0.29$ & $12.1 \pm 0.84^{\mathrm{c}}$ & $28.1 \pm 2.6^{\mathrm{c}}$ & $10.2 \pm 1.1^{\mathrm{a}}$ & $12.4 \pm 1.2^{\mathrm{c}}$ \\
\hline
\end{tabular}

Data expressed mean $\pm \mathrm{SD},{ }^{\mathrm{a}} \mathrm{P}<0.05,{ }^{\mathrm{b}} \mathrm{P}<0.01$ and ${ }^{\mathrm{c}} \mathrm{P}<0.001$

Table (3): Catalase (CAT) $(\mathrm{u} / \mathrm{min} / \mathrm{g})$, Na,K-ATPase $\left(\mu \mathrm{mol} \mathrm{p}_{\mathrm{i}} / \mathrm{min} / \mathrm{g}\right)$ and lactate dehydrogenase $(\mathrm{LDH})(\mathrm{U} / \mathrm{L})$ in different tissues:

\begin{tabular}{|c|c|c|c|c|c|c|}
\hline 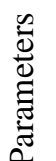 & Tissues & $\begin{array}{l}\text { (group I) } \\
\text { Control }\end{array}$ & $\begin{array}{l}\text { (group II) } \\
\text { VPA 30d }\end{array}$ & $\begin{array}{l}\text { (group III) } \\
\text { VPA 60d }\end{array}$ & $\begin{array}{c}\text { (group IV) } \\
\text { VPA 30d } \\
\text { \& L-CAR }\end{array}$ & $\begin{array}{l}\text { (group V) } \\
\text { VPA 60d } \\
\text { \& L-CAR }\end{array}$ \\
\hline \multirow{4}{*}{ 它 } & Muscle & $4.4 \pm 0.34$ & $1.6 \pm 0.15^{\mathrm{c}}$ & $0.90 \pm 0.05^{\mathrm{c}}$ & $3.9 \pm 0.25^{\mathrm{c}}$ & $1.5 \pm 0.19^{c}$ \\
\hline & Brain & $5.6 \pm 0.09$ & $2.4 \pm 0.25^{\mathrm{c}}$ & $0.94 \pm 0.15^{\mathrm{c}}$ & $4.3 \pm 0.3^{c}$ & $3.8 \pm .09^{c}$ \\
\hline & Bone & $4.7 \pm 0.13$ & $2.5 \pm 0.01^{\mathrm{c}}$ & $1.2 \pm 0.05^{\mathrm{c}}$ & $3.6 \pm 0.19^{c}$ & $1.8 \pm 0.16^{\mathrm{c}}$ \\
\hline & Liver & $5.6 \pm 0.52$ & $1.9 \pm 0.18^{\mathrm{c}}$ & $1.1 \pm 0.09^{c}$ & $3.3 \pm 0.37^{\mathrm{c}}$ & $2.8 \pm 0.09^{c}$ \\
\hline \multirow{4}{*}{ 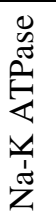 } & Muscle & $56.8 \pm 2.1$ & $36.1 \pm 2.7^{\mathrm{c}}$ & $24.8 \pm 3.1^{\mathrm{c}}$ & $40.9 \pm 1.7^{b}$ & $23.9 \pm 0.25$ \\
\hline & Brain & $62.1 \pm 2.9$ & $45.14 \pm 2.9^{c}$ & $32.8 \pm 2.6^{c}$ & $48.1 \pm 0.9$ & $40.5 \pm 1.3^{\mathrm{c}}$ \\
\hline & Bone & $60.4 \pm 0.38$ & $30.3 \pm 0.13^{\mathrm{c}}$ & $22.2 \pm 0.25^{\mathrm{c}}$ & $42.8 \pm 0.59^{\mathrm{a}}$ & $25.7 \pm 2.6^{b}$ \\
\hline & Liver & $56.3 \pm 0.4$ & $35.5 \pm 2.2^{\mathrm{c}}$ & $22.8 \pm 1.02^{\mathrm{c}}$ & $40.3 \pm 2.1^{\mathrm{b}}$ & $24.91 \pm 1.1^{\mathrm{c}}$ \\
\hline \multirow{4}{*}{$\stackrel{\bar{I}}{\mathrm{G}}$} & Muscle & $82.9 \pm 1.7$ & $141.8 \pm 1.9^{c}$ & $152.1 \pm 2.6^{\mathrm{c}}$ & $123.7 \pm 0.9^{c}$ & $132 \pm 2.1^{\mathrm{c}}$ \\
\hline & Brain & $78.6 \pm 4.4$ & $128.6 \pm 4.1^{\mathrm{c}}$ & $276.7 \pm 4.9^{\mathrm{c}}$ & $116.6 \pm 3.4^{\mathrm{c}}$ & $194.5 \pm 3.2^{\mathrm{c}}$ \\
\hline & Bone & $77.3 \pm 2.4$ & $114.9 \pm 1.9^{c}$ & $328.8 \pm 4.2^{\mathrm{c}}$ & $186.7 \pm 3.4^{\mathrm{c}}$ & $225.8 \pm 1.7^{\mathrm{c}}$ \\
\hline & Liver & $218.6 \pm 1.4$ & $345.8 \pm 11.7^{\mathrm{c}}$ & $418.1 \pm 4^{c}$ & $279.3 \pm 9.6^{\mathrm{c}}$ & $286.5 \pm 3.2^{\mathrm{c}}$ \\
\hline
\end{tabular}

Data expressed mean \pm SD, ${ }^{\mathrm{a}} \mathrm{P}<0.05,{ }^{\mathrm{b}} \mathrm{P}<0.01$ and ${ }^{\mathrm{c}} \mathrm{P}<0.001$ 


\section{Discussion}

In the present study, the administration of sodium valproate caused a significant increase in the levels of lipid profile variables (cholesterol, triglycerides, phospholipids and free fatty acids). The cytotoxic activity of valproate is the result of the generation of hydrogen peroxide and the production of highly reactive hydroxyl radicals (Tabatabaei and Abbott, 1999). This could lead to the increased levels of thiobarbituric acid reactive substances (TBARS) and decreased levels of enzymatic (CAT) in the Groups II and III. Further sodium valproate treatment through a process of free radical damage causes functional damage in the liver (Siddique et al., 1999). It has been reported that sodium valproate VPA treatment caused inhibition of TCA cycle at an enzymatic step distal to $\alpha$-ketoglutarate dehydrogenase e.g., succinate dehydrogenase or fumarase (Johannessen et al., 2001). It could elevate the levels of acetyl CoA and this may be used for the synthesis of fatty acids and cholesterol, since fatty acids of different sources are used as substrates for synthesizing triglycerides and phospholipids. Further treatment with valproate causes induction of mitochondrial cytopathy with microvesicular lipid deposition. The lipid deposits are likely to be a result of the inhibited mitochondrial fatty acid oxidation (Melegh and Trombitas, 1997). The enhanced level of lipid profile variables could be due to the carnitine transport defect associated with the treatment of sodium valproate. Our results are in accordance with the report of Heldenberg et al. (1983) who found an increase in cholesterol levels in epileptic children treated with VPA. In this work, CARN reduced serum lipid and fatty acids levels in VPA-treated rats. The level of cholesterol in sera was significantly decreased with total fatty acids after the addition of CARN (Hong et al., 2002).Upon CARN administration, a decrease in lipid peroxidation was observed (Kalaiselvi and Panneerselvam, 1998). This may have been due to its active role in the transport of fatty acids for energy production, thereby lowering the availability of lipids for production.

L-carnitine is an antioxidant and prevents the accumulation of end products of lipidoxidation (Fabriello and Calabrese, 1988; Lowitt et al., 1995 and Gulcin, 2006). It is synthesized from two essential amino acids, lysine and methionine. In addition, carnitine is transported to skeletal and cardiac muscles after its major production in liver and kidney, and it transports acyl-CoA acids into the mitochondrial matrix for h-oxidation of free fatty acids (Brevetti and Perna, 1992; Visioli et al., 1992).Carnitine is known to stimulate fatty acid oxidation (Fritz, 1963) and the oxidative removal of pyruvate (Ferrannini et al., 1988), both leading to increased ATP generation and limited lactate production. It was one of the most important discoveries regarding the energy metabolism of the cell that the long-chain fatty acids required L-CAR as a cofactor for penetrating the inner mitochondrial membrane (Bremer, 1997). The fatty acid intake is achieved by the cooperation of the enzymes carnitinepalmitoyl transferases I and II (Fritz and Yue, 1963) and the carnitine-acylcarnitine translocase (Pande, 1975). The activities of these enzymes are responsible for the function of fatty acid-carnitine exchange through the inner mitochondrial membrane. Because L-CAR in this way plays an important role in this transport processes. So, L-CAR supplementation by virtue of its ability to enhance ATP production (Coni et al., 1994) might improve the overall enzyme synthesis in cells (Kalaiselvi and Pannerselvam, 1998). Moreover CARN, being an antioxidant, can protect these enzymes from further peroxidative damage and this may be reflect the alleviation of $\mathrm{Na}, \mathrm{K}-\mathrm{ATPase}$ and LDH activities .

\section{Conclusion}

The long term administration of sodium valproate causes initiation and propagation of oxidative stress as showed by the increase of 
lipid peroxidation and decrease of catalase activity in different investigated tissues. This may be significantly increasing the levels of lipid profile variables (cholesterol, triglycerides, phospholipids and free fatty acids). On the other hand, the decrease in the activities of lactate dehydrogenase and $\mathrm{Na}, \mathrm{K}$ - ATPase reflect the metabolic changes in energy state of sodium valproate-treated groups. As Lcarnitine ameliorates the deflection of these physiological parameters, so it might be recommended for epileptic patients subjected to sodium valproate for long time.

\section{Reference}

1. Acker M A, Hammond RC, Mannion J D, Salmons $S$ and Stephenson LW (1986): An autologus biologic pump motor. J. Thorac. Cardiovasc. Surg., 92: 733-746.

2. Baginiski E B, Ipstein E, and Zak B., (1972): Determination of phospholipids in plasma. Ann. Clin. Lab. Sci., 2, 255-260.

3. Binienda $\mathbf{Z}$ K and Ali S F, (2001): Neuroprotective role of 1-carnitine in the 3nitropropionic acid induced neurotoxicity. Toxicol. Lett., 125, 67-73.

4. Bohan TP, Helton E and McDonald I, (2001): Effect of L-carnitine treatment for valproate-induced hepatotoxicity. Neurol., 56 (10):1405-9.

5. Bremer J (1997): The role of carnitine in cell metabolism. In DeSimone C. Famularog (eds): Carnitine today. Berlin Germany, Springer: 1-37.

6. Brevetti G and Perna S (1992): Metabolic and clinical effects of 1-carnitine in peripheral vascular disease. In: Ferrari, R., DiMauro, S., Sherwood, G. (Eds.), 1-carnitine and its Role in Medicine: From Function to Therapy. Academic Press, London, pp. 359- 378.

7. Brevetti G, Attisano T, Prena S, Rossini A, Policicchio A and Corsi M (1989): Effect of L-carnitine on the reactive hyperemia in patients affected by peripheral vascular disease; a double blind crossover study. Angiol., 40: 857-862.

8. Brown GG (1999): Nitric oxide and mitochondrial respiration. Biochimica and Biophysica Acta , 1411: 351- 369.

9. Buchi KN, Gray PD, Rollins DE and Tolman KG (1984): Protection against sodium valproate injury in isolated hepatocytes by alpha-tocopherol and N, N'diphenyl -p- phenylenediamine. J. Clin. Pharmacol., 4:148-54.

10. Cadenas E and Davies KJ (2000): Mitochondrial free radical generation, oxidative stress, and aging. Free Radic. Biol. Med, : 222-230.

11. Coulter DL (1995): Carnitine deficiency in epilepsy: Risk factors and treatment. J Child Neurol., 10 ( 2): S32-9.

12. Defoort EN, Kim PM and Winn LM (2006): Valproic acid increases conservative homologous recombination frequency and reactive oxygen species formation: a potential mechanism for valproic acid-induced neural tube defects. Mol. Pharmacol., 69(4):130410.

13. DeVane CL (2003): Pharmacokinetics, drug interactions, and tolerability of valproate. Psychopharmacol Bull, 37 (2): 25-42.

14. Dhalla NS, Temsha RM and Netticadan T (2000): Role of oxidative stress in cardiovascular diseases. J. Hypertens, 18: 655-73.

15. Dayanandan A, Kumar $\mathbf{P}$ and Panneerselvam C (2001): Protective role of L-carnitine on liver and heart lipid peroxidation in atherosclerotic rats. J. Nutr Biochem., 12: 254-257.

16. Fabriello RG and Calabrese F (1988): Prevention of ischemia induced increase in MDA by acetyl carnitine. Ann Neurol., 24, 114-118.

17. Falholt K, Lund B and Falholt W (1973): An easy colorimetric micromethod for routine determination of free fatty acids in plasma. Clin. Chim. Acta, 46: 105-111.

18. Fernandez-Checa JC, Garcia-Ruiz C, Colell A, Morales A, Mari M, Miranda M and Ardite E (1998): Oxidative stress: Role of mitochondria and protection by glutathione. Biofactors, 8:7-11.

19. Foster LB and Dunn RT (1973): Stable reagents for determination of serum triglycerides by a colorimetric Hantzsch condensation method. Clin. Chem., 19:338-340.

20. Frings CS, Fendley TW, Dunn RT, and Queen CA, (1972): Improved determination of total serum lipids by the sulfo-phosphovanillin reaction. Clin Chem, 18 (7), 673-674.

21. Gulcin I, (2006): Antioxidant and antiradical activities of 1-carnitine. Life Sciences, 78: 803 $-811$.

22. Kalaiselvi $T$ and Panneerselvam C, (1998): Effect of 1-carnitine on the status of lipid peroxidation and antioxidants in aging rats. $\mathbf{J}$ Nutr Biochem., 9: 575-581. 
23. Kobayashi A and Fujisawa S (1994): Effect of L-carnitine on mitochondrial acylCoA esters in the ischemic dog heart. J Mol Cell Cardiol, 26: 499-508.

24. Kremser K, Stangl H, Pahan K, and Singh I (1995): Nitric oxideregulates peroxisomal enzyme activities. Europane J Clinic Chem and Clinic Biochem, 33, 763-774.

25. Loscher W, and Vetter $M$ (1985). In vivo effects of aminooxyacetic acid and valproic acid on nerve terminal (synaptosomal) GABA levels in discrete brain areas of the rat. Biochem. Pharmacol, 34, 1747-1756.

26. Lowitt S, Malone JI, Salem AF, Korhals J and Benford S (1995): Acetyl-lcarnitine corrects the altered peripheral nerve function of experimental diabetes. Metabolism, 445: 677-680.

27. Marnett LJ (2000): Oxyradicals and DNA damage. Carcinogenesis, 21:361-370.

28. Mayes PA (2000): Lipids of physiologic significance. In: Murray, R.K., Granner, D.K., Mayes, P.A., Rodwell, V.W. (Eds.), Harper's Biochemistry, (25th ednR)Appleton and Lange, Stamford, pp. 160- 171.

29. McLean $M$ and Macdonald $R$ (1986): Sodium valproate, but not ethosuximide, produces use-and voltage-dependent limitation of high frequency repetitive firing of action potentials of mouse central neurons in cell culture. J Pharmacol. Exp. Therapeut, 237, 1001-1011.

30. Melegh B and Trombitas K (1997): Valproate treatment induces lipid globule accumulation with ultrastructural abnormalities of mitochondria in skeletal muscle. Neuropediatrics, 28: 256-261.

31. Ohkawa H, Ohishi N and Yagi K (1979): Assay for lipid peroxides in animal tissues by thiobarbituric acid reaction. Anal Biochem., 95: 351-8.

32. Raabo E (1963): Determination of serum lactic dehydrogenase by the tetrazolium salt method. Scard. J. Clin. Lab. Invest., 15:233.

33. Ramsay RR (1999): The role of the carnitine system in peroxisomal in fatty acid oxidation. Amer J Med Sci., 318, 28- 35.
34. Rowan AJ (1997): Valproate. In Engel J., Pedley T.A (eds.): Epilepsy: A comprehensive textbook, Lippincott-Raven Publ., Philadelphia, pp. 1599-1607.

35. Sabayan B, Foroughinia $\mathbf{F}$ and Chohedry A (2007): A postulated role of garlic organosulfur compounds in prevention of valproic acid hepatotoxicity. Medical Hypotheses, 68: 512-514.

36. Siddique MAA, Nazmi AS, and Razia K (1999): Oxidative damage in mice liver induced by sodium valproate: protection by melatonin. Indian J. Pharmacol., 31: 427-431.

37. Sinha AK: (1972): Colorimetric assay of catalase. Anal. Biochem., 47: 389-394.

38. Tabatabaei AR and Abbott FS (1999): Assessing the mechanism of metabolismdependent valproic acid-induced in vitro cytotoxicity. Chem. Res. Toxicol., 12: 323330.

39. Tong V, Chang TK, Chen J and Abbott FS (2003): The effect of valproic acid on hepatic and plasma levels of 15-F2t-isoprostane in rats. Free Radical Biol Med., 34 (11): 143546.

40. Tong V, Teng XW, Chang TK and Abbott FS (2005): Valproic acid II: effects on oxidative stress, mitochondrial membrane potential, and cytotoxicity in glutathionedepleted rat hepatocytes. Toxicol Sci., 86 (2): 436-443.

41. Uziel G, Garavaglia B, and Di Donato S, (1988): Carnitine stimulation of pyruvate dehydrogenase complex (PDHC) in isolated human skeletal muscle mitochondria. Muscle Nerve, 11: 720-724.

42. Visioli O, Pasini E, de Giuli F, and Ferrari R (1992): Molecular mechanism of action of 1-carnitine in treatment of myocardial disorders at the experimental levels. In: Ferrari, R., DiMauro, S., Sherwood, G. (Eds.), l-carnitine and Its Role in Medicine: From Function to Therapy. Academic Press, London, pp. 237- 263.

43. Zlatkis A, Zak B and Boyle AJ (1953): A new method for the direct determination of serum cholesterol. J. Lab. Clin. Med., 41: 486-492. 


\section{تأثير الكارنتين على الاضطر ابات الفسيولوجية المستحثة بواسطة فالبروات الصوديوم فى الجرذان البيضاء}

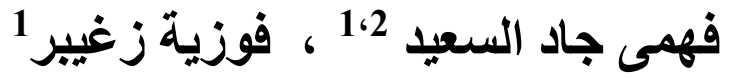

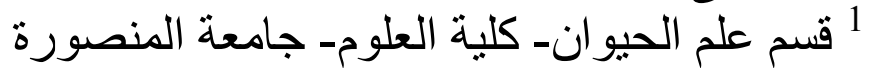

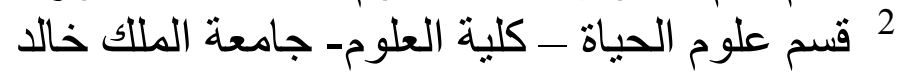

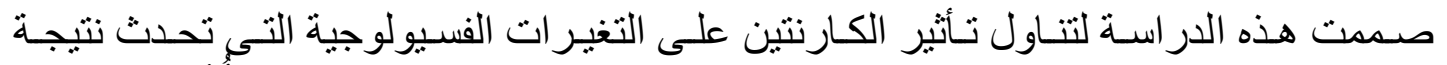

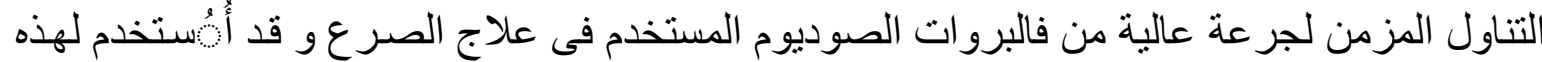

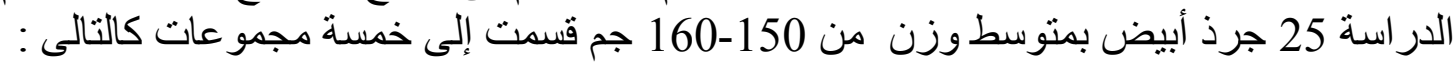

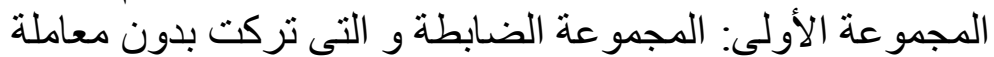

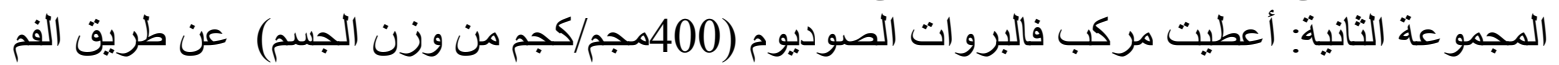

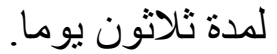

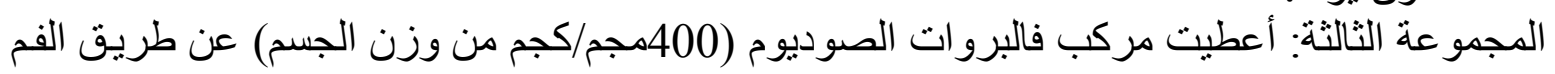

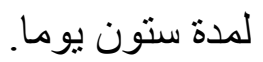

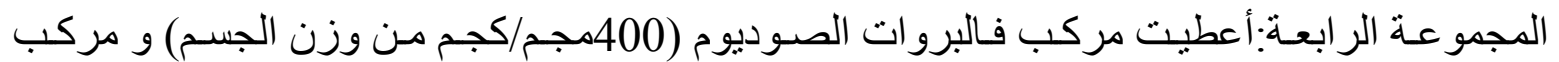

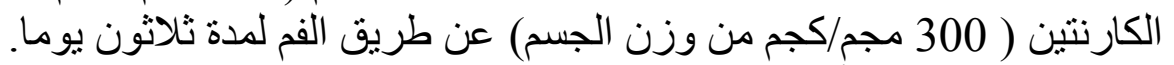

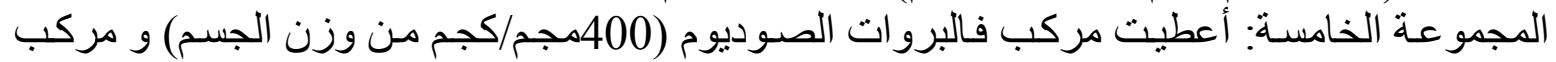

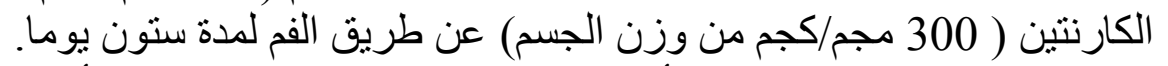

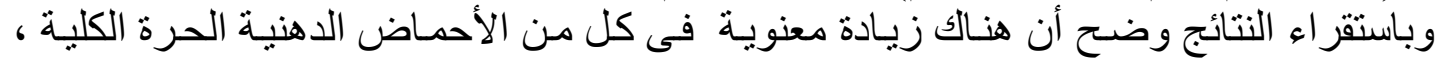

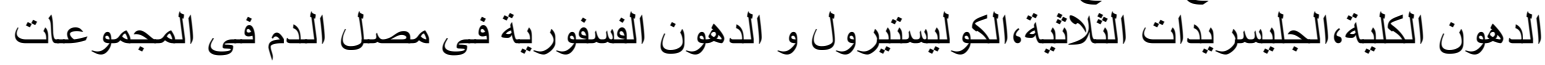

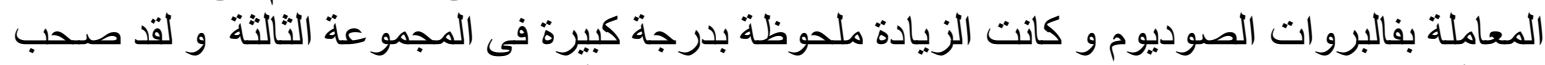

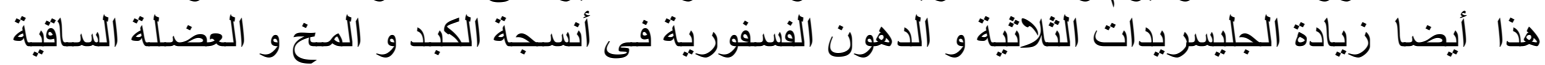

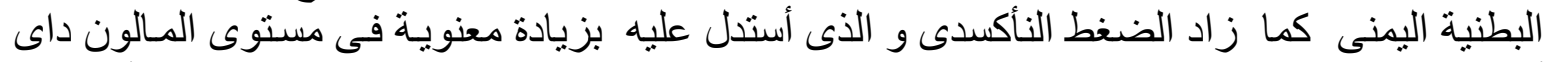

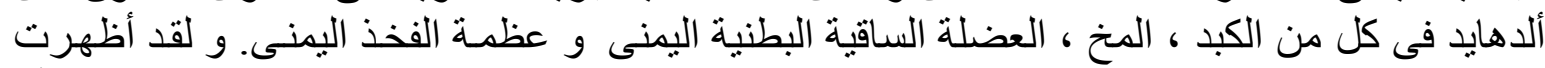

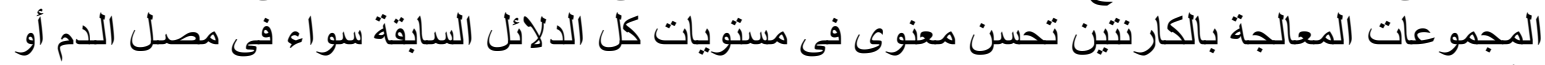
الأنسجة المختلفة.

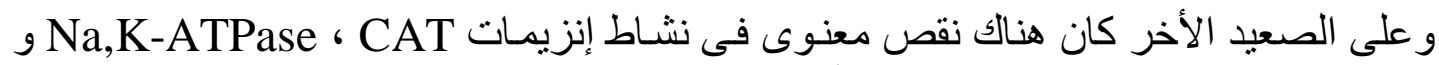

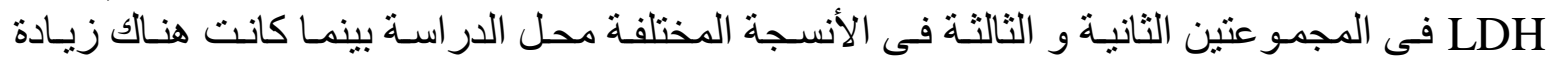

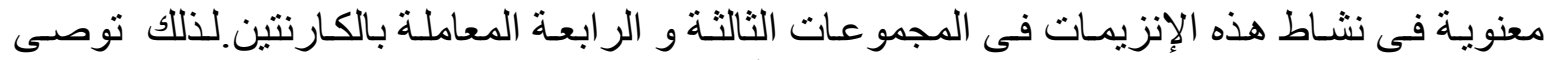

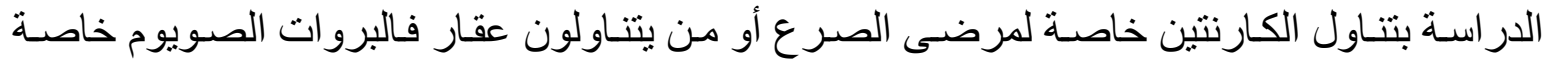
لفترات زمنية طويلة. 